\title{
Endovascular Therapy of 103 Aneurysms in the Internal Carotid Artery with Flow Re-Direction Endoluminal Device
}

\section{Terapia endovascular de 103 aneurismas na artéria carótida interna com dispositivo endoluminal de redirecionamento de fluxo}

\author{
Vinicius Fialho Teixeira1(1) Albedy Moreira Bastos ${ }^{1,2(0)}$ Rafael Brito Santos ${ }^{1,2(1)}$ \\ ${ }^{1}$ Neurology and Neurosurgery Department, Universidade Estadual do \\ Address for correspondence Vinicius Fialho Teixeira, Medical \\ Pará (UEPA), Belém do Pará, PA, Brazil \\ Student. Tv. Perebebuí, 2623 - Marco, Belém, PA, 66087-662, Brazil \\ 2 Neurology and Neurosurgery Department, Service of Neurosurgery \\ (e-mail: viniciusfialhoteixeira@gmail.com).
}

of Universidade Estadual do Pará UEPA), Belém do Pará, PA, Brazil

Arq Bras Neurocir 2023;42(1):e19-e23.

\begin{abstract}
Objective Intracranial aneurysms (Als) are acquired vascular abnormalities that cause sacculations in the arterial wall and are present in $\sim 2$ to $5 \%$ of the population. Among the treatment options are endovascular interventions with the use of flow-redirecting stents. In the present study, we analyzed the flow re-direction endoluminal device (FRED).

Methods The present study aims to describe the results obtained from treatment with FRED in a series of patients affected by aneurysms in intracranial segments of the internal carotid artery. This is a cross-sectional, epidemiological, and observational study, whose data were obtained from the medical records of 81 patients from July 2018 to July 2019.

Results One hundred and three internal carotid artery aneurysms were observed in 81 patients, with a prevalence of women $(91.35 \%)$, small $(<10 \mathrm{~mm})(89.33 \%)$, and located at the $\mathrm{C} 6$ level (73.78\%) of the internal carotid artery. Of the 81 patients, 16 had multiple aneurysms in the same artery. One hundred and three FRED stents were used in the treatment. These patients underwent angiography 6 months after the surgery,

Keywords

- stent

- aneurysm

- endovascular

- treatment using the O'Kelly-Marotta classification (OKM) to assess the effectiveness of the device, and it was observed that: in 91 of the 103 procedures (88.34\%), the FRED was fully open and well positioned, thus restoring the arterial flow and leading to a statistically significant result. In addition, a low complication rate (4.85\%) was found, with ischemic stroke being the main complication (1.94\%).
\end{abstract}

received

February 8, 2021

accepted

April 12, 2021
DOI https://doi.org/

10.1055/s-0041-1740021. ISSN 0103-5355. (c) 2021. Sociedade Brasileira de Neurocirurgia. All rights reserved. This is an open access article published by Thieme under the terms of the Creative Commons Attribution-NonDerivative-NonCommercial-License, permitting copying and reproduction so long as the original work is given appropriate credit. Contents may not be used for commercial purposes, or adapted, remixed, transformed or built upon. (https://creativecommons.org/ licenses/by-nc-nd/4.0/)

Thieme Revinter Publicações Ltda., Rua do Matoso 170, Rio de Janeiro, RJ, CEP 20270-135, Brazil 


\section{Resumo}

\section{Palavras-chave \\ - stent \\ - aneurisma \\ - endovascular \\ - tratamento}

Conclusion This device can be an effective option in the treatment of internal carotid aneurysms since the aneurysm occlusion rate is excellent with a low rate of complications.

Objetivo Aneurismas intracranianos (Als) são anormalidades vasculares adquiridas, presentes em aproximadamente 2 a $5 \%$ da população, que causam saculações na parede arterial. Entre as opções de tratamento, estão as intervenções endovasculares com uso de stents de redirecionamento de fluxo. Neste estudo, analisamos o dispositivo de redirecionamento de fluxo endoluminal (FRED, na sigla em inglês).

Métodos Este estudo tem como objetivo descrever os resultados obtidos no tratamento com FRED em uma série de pacientes acometidos por aneurismas em segmentos intracranianos da artéria carótida interna. Trata-se de um estudo transversal, epidemiológico e observacional, cujos dados foram obtidos dos prontuários de 81 pacientes no período de julho de 2018 a julho de 2019.

Resultados Foram observados 103 aneurismas da artéria carótida interna em 81 pacientes, com a prevalência de mulheres $(91,35 \%)$, aneurismas de pequeno porte $(<$ $10 \mathrm{~mm})(89,33 \%)$ e localizados no nível C6 (73,78\%) da artéria carótida interna. Dos 81 pacientes, 16 apresentaram múltiplos aneurismas na mesma artéria. Cento e três stents FRED foram utilizados no tratamento. Esses pacientes foram submetidos à angiografia 6 meses após a cirurgia, e utilizando a classificação de O’Kelly-Marotta (OKM) para avaliar a eficácia do dispositivo, observou-se que em 91 dos 103 procedimentos $(88,34 \%)$, o FRED estava totalmente aberto e bem-posicionado, levando assim à restauração do fluxo arterial e a um resultado estatisticamente significante. Além disso, foi encontrado baixo índice de complicações (4,85\%), sendo o acidente vascular cerebral isquêmico a principal complicação (1,94\%).

Conclusão Este dispositivo pode ser uma opção eficaz no tratamento dos aneurismas carotídeos internos, visto que a taxa de oclusão do aneurisma é excelente com baixa taxa de complicações

\section{Introduction}

Intracranial aneurysms (IAs) are acquired vascular abnormalities that cause sacculations in the arterial wall. They are often located at the bifurcation of the arteries in the anterior circulation of the Willis polygon. ${ }^{1}$ In addition, IAs are present in $\sim 2$ to $5 \%$ of the population and are the most common cause of non-traumatic, spontaneous subarachnoid hemorrhage. ${ }^{2}$

Flow redirectors (FRs) have clearly revolutionized the endovascular treatment of aneurysms. The two main principles on which the concept was founded are diversion of blood flow away from the aneurysm, inducing stasis and thrombosis within the aneurysm sac and endothelialization along the stent scaffold and restoration of the integrity of the arterial wall. $^{3}$

There are several FRs available for clinical use, including, among others, the pipeline embolization device (PED; Covidien, Irvine, CA, USA); the SILK flow diverter (SILK; Balt Extrusion, Montmorency, France), and the Surpass (Surpass; Stryker Neurovascular, Fremont, CA, USA). The endoluminal flow redirection device (FRED; MicroVention, Tustin, CA, USA) is a relatively new FR. There are limited reports on the clinical results of its use. ${ }^{4-7}$
A large European study ${ }^{8}$ observed a global rate of complete aneurysm obliteration of $69.2 \%$, with a progressive increase in the proportion of aneurysms occluded within the duration of the follow-up, which reached a rate of $83.9 \%$ of complete occlusion in aneurysms followed-up by at least 1 year . In that same study, ${ }^{8}$ transient and permanent morbidity occurred in $3.2 \%$ and $0.8 \%$ of procedures, respectively, with an overall mortality rate of $1.5 \%$, and another study ${ }^{9}$ pointed out the effectiveness of this device in $84.32 \%$ of cases, with $66 \%$ presenting aneurysm occlusion in the $1^{\text {st }}$ year and 101 out of 109 (92.7\%) posteriorly.

The FRED device is still new in the FRs market, with few studies on it; therefore, the present study aimed to evaluate the endovascular treatment of 103 intracranial aneurysms in 81 patients with FRED.

\section{Methods}

\section{Ethical Aspects}

All patients who participated in the present study were studied according to the precepts of the Declaration of Helsinki and the Nuremberg Code, respecting the Research Standards Involving Human Beings (Res. CNS 466/12) of the 
National Health Council. The patients were included after ethical approval was obtained by the responsible institution

\section{Casuistry}

The inclusion criteria were patients with non-ruptured aneurysms, located in the $\mathrm{C} 3$ to $\mathrm{C} 7$ segments of the internal carotid artery, according to the anatomical division of Bouthillier et al. (1996), ${ }^{10}$ regardless of the size of the aneurysm, age or gender of the patients, to simulate real-life visits. All patients were clinically stable at the time of surgery, which followed the protocols with antiplatelet agents and postoperative follow-up described later in the present article. All patients were treated with a FRED stent, and no patient was treated with another method before FRED. The surgeries were performed by professionals from the neurosurgery and endovascular surgery team in a specialized center from July 2018 to July 2019.

\section{Antiplatelet Agents}

The antiplatelet therapy established for all was performed as follows: prasugrel $10 \mathrm{mg}$ started 7 days before the surgical procedure, and subsequently maintained for 6 months after the treatment. After this period, the use of prasugrel $10 \mathrm{mg}$ should be discontinued, and the use of $100 \mathrm{mg}$ of acetyl salicylic acid should be maintained for the rest of the patient's life.

\section{Stent Choice}

We chose to add the aneurysms eligible for FRED. For correct choice of the device used, all patients underwent digital subtraction angiography with three-dimensional volumetric reconstruction, using a biplane angiographic system to outline the length and anatomy of the aneurysm as well as to measure the proximal and distal diameters of the main artery in which the device was to be implanted. Because the ideal diameter of the FRED is the maximum diameter of the artery in which it is being implanted, it generally corresponds to the arterial diameter proximal to the aneurysm. The selection of the FR size is crucial to promote a safe and complete aneurysm occlusion. ${ }^{11}$ In addition, the selection of the working length for flow deviation was based on the coverage of the neck of the aneurysm or the length of the fusiform or dissecting aneurysm with a margin of 2 to $4 \mathrm{~mm}$ at the proximal and distal ends, which represents only the length of the layer stent. Currently, FRED is available in 5 different diameters $(3.5,4.0,4.5,5.0$, and $5.5 \mathrm{~mm})$ recommended for vessel diameters ranging from 2.5 to $5.5 \mathrm{~mm}$ and working lengths (double layer cover) from 7 to $56 \mathrm{~mm}$. A Chaperon catheter (MicroVention Inc., Aliso Viejo, CA USA), a Headway 27 microcatheter (MicroVention), and Traxcess 14 microwire guides (MicroVention) were used in all cases to choose the ideal model in the present study.

\section{Description of the Technique}

All procedures were performed with the patient under general anesthesia and through a unilateral femoral access. The implantation technique involves advancing the Headway microcatheter distal to the aneurysm and is partially partially implanting the initial part of the FRED. The device is then returned to the desired position and implanted slowly under constant fluoroscopy, ensuring that there is a good overlap of the stent against the vessel lumen. Two angiographic views are used to ensure this, and satisfactory positioning is confirmed with fluoroscopy. If the device is not positioned correctly on the neck of the aneurysm, the stent must be repositioned, provided that $80 \%$ of its length has been implanted. The aneurysm must be centered within the double layer of the FRED, and only the working length must cover the aneurysm to guarantee the flow deviation. ${ }^{12}$

\section{Follow-Up}

The 12-month treatment and posttreatment were evaluated for the degree of filling and flow stasis in the aneurysm with arteriography using the O'Kelly-Marotta (OKM), ${ }^{13}$ according to which each aneurysm is classified with a letter, representing the degree of filling (A, total filling; B, subtotal filling; C, remaining input; $D$, no filling). This degree is followed by a number, which represents the degree of stasis (stasis in 1 , arterial phase; 2 , capillary phase; 3 , venous phase). This monitoring was performed by the research team at the responsible institution and served as a basis for analyzing the effectiveness of the treatment.

\section{Statistical Analysis}

The data obtained were analyzed using the Biostat 5.3 software (Tefé, Amazonas, Brazil), using the chi-squared test, with a $p$-value $<0.05$ and the $95 \%$ confidence interval in the hypothesis testing related to the device's effectiveness rates.

\section{Results}

\section{Characteristics}

A total of 81 patients were included in this research, as shown in ( - Table 1), 7 of whom were male (8.65\%) and 74 of whom were female (91.35\%). A 10.57 female prevalence ratio was presented. In addition, the average age found was $\sim 52$ years, with 24 and 72 years as the extremes of age.

Although 81 patients were included in the study, a total of 103 aneurysms were found. This is justified by the occurrence of multiple aneurysms in the internal carotid segments of 16 of these participants (19.75\%). Therefore, in relation to the total number of aneurysms found, the segments with the highest incidence were: C6 (73.78\%); C7 (16.50\%); C4 (6.71\%), and C5 (2.91\%); however, no aneurysm was recorded in segment C3.

Regarding the size of the aneurysms, an average length of $5.23 \mathrm{~mm}$ was found, with the smallest and largest being $1 \mathrm{~mm}$ and $26 \mathrm{~mm}$, respectively. Therefore, of the total of 103 aneurysms, the following was found in relation to their length: there were 90 (87.37\%) small $(<10 \mathrm{~mm}) ; 11(10.67 \%)$ large (10-25 mm), and 2 (1.94\%) giant aneurysms (> $25 \mathrm{~mm}$ ).

\section{Efficacy}

The success rates in the procedure with aneurysm occlusion, fully open and well positioned stent with restoration of arterial flow, corresponded to 91 of the 103 procedures 
Table 1 Epidemiological characteristics of patients with aneurysms located in the internal carotid artery, treated with flow re-direction endoluminal device, in a single center

\begin{tabular}{|l|l|}
\hline Gender & \\
\hline Male & $7(8.65 \%)$ \\
\hline Female & $74(91.35 \%)$ \\
\hline TOTAL & $81(100 \%)$ \\
\hline Age (years) & $24-73(51.79$ mean) \\
\hline Aneurysm location & \\
\hline C3 & $0(0 \%)$ \\
\hline C4 & $7(6.71 \%)$ \\
\hline C5 & $3(2.91 \%)$ \\
\hline C6 & $76(73.78 \%)$ \\
\hline C7 & $17(16.50 \%)$ \\
\hline TOTAL & $103(100 \%)$ \\
\hline Aneurysm size & \\
\hline Small $(<10 \mathrm{~mm})$ & $90(87.37 \%)$ \\
\hline Large $(10-25 \mathrm{~mm})$ & $11(10.67 \%)$ \\
\hline Giant $(>25 \mathrm{~mm})$ & $2(1.94 \%)$ \\
\hline TOTAL & $103(100 \%)$ \\
\hline
\end{tabular}

Abbreviation: FRED, flow re-direction endoluminal device. Source: Patient records.

Note: In the study, 16 patients presented with 2 or more aneurysms.

(88.34\%). These results are compatible with OKM classifications $C$ and $D$. There were 4 subocclusions (3.88\%), corresponding to classification $B$, and 8 aneurysms did not obtain occlusion (7.76\%), corresponding to classification A ( $p$-value $<0.01)$. In these variables, these data were obtained with outpatient monitoring and angiography control 12 months after the procedure, as shown in - Table 2.

Regarding major complications, there were a total of 5 patients (4.85\%) affected. In the intraoperative period, there was poor opening of the stent and dissection of the femoral artery, through which endovascular materials entered, both with an incidence of $0.97 \%$ each. Consequently, there were 2 acute strokes in the postoperative period of up to 7 days, and a carotid-cavernous fistula, being responsible respectively for $(40 \%)$ and $(20 \%)$ of the total complications, as shown in -Table 3.

\section{Discussion}

In the present study, it was observed that the female gender predominated in the total of consultations, with 74 patients (91.35\%), compared with only 7 male patients (8.65\%). In addition, the average age found was of $\sim 52$ years for the diagnosis of aneurysms, which is in accordance with previous studies. Regarding the epidemiology of this pathology, it was pointed out that female gender and age are also nonmodifiable risk factors for carotid aneurysms, which was observed in a meta-analysis of 95,000 patients; similar results were also found by Wang, et al. in $2014 .^{2}$ In addition,
Table 2 Evaluation of the degree of filling and flow stasis in the aneurysm using the O'Kelly-Marotta classification scale in the treatment of internal carotid artery aneurysms

\begin{tabular}{|l|l|l|}
\hline STENT-FRED & Nr. of aneurysms & $\%$ \\
\hline OKM & & \\
\hline C-D & 91 & $88.34 \%^{*}$ \\
\hline B & 4 & $3.88 \%$ \\
\hline A & 8 & $7.76 \%$ \\
\hline Total & 103 & $100.00 \%$ \\
\hline
\end{tabular}

Abbreviations: Nr.: number; OKM, O’Kelly-Marotta.

Source: Patient records.

Note: (A, total filling; B, subtotal filling; C, remaining entry; D, without filling).

${ }^{*}$ chi-squared test with $p<0.05\left(x^{2}=43.220 ; p\right.$-value $\left.=0.0001\right)$.

Table 3 Complications in patients with aneurysms treated with flow re-direction endoluminal device

\begin{tabular}{|l|l|l|l|}
\hline Complications & $\begin{array}{l}\text { Nr. of } \\
\text { patients }\end{array}$ & $\begin{array}{l}\text { Nr. of } \\
\text { complications }\end{array}$ & $\%$ \\
\hline Intrasurgical & & & \\
\hline Stent's bad opening & 11 & 1 & $0.97 \%$ \\
\hline Femoral artery dissection & 80 & 1 & $0.97 \%$ \\
\hline Postoperative (until 7 days) & & & \\
\hline Acute ischemic stroke & $8-19$ & 2 & $1.94 \%$ \\
\hline Late (> 7 days) & & & \\
\hline Carotid-cavernous fistula & 39 & 1 & $0.97 \%$ \\
\hline Total & & 5 & $4.85 \%$ \\
\hline
\end{tabular}

Abbreviations: FRED, flow re-direction endoluminal device; Nr., number. Source: Patient records.

the average age found in the literature was 50 years, ranging from 22 to 76 years. ${ }^{14}$

Even though there were 83 patients, the total number of aneurysms found was 103 . This can be explained because 16 patients (19.27\%) had multiple aneurysms, a result higher than that found by Binh et al. in $2020,{ }^{14}$ who pointed to a ratio of $11,90 \%$ incidence of multiple aneurysms in their study. The interesting thing observed in our analysis was that all patients with multiple aneurysms were affected on the same side.

Regarding the size of the aneurysms, we found: 90 (87.37\%) small (< $10 \mathrm{~mm}) ; 11(10.67 \%)$ large $(10-25 \mathrm{~mm})$, and $2(1.94 \%)$ giant aneurysms $(>25 \mathrm{~mm})$. The largest number of small aneurysms is widely found in the literature. $^{14-16}$

Our study evaluated the viability of the flow in the artery during surgery and after 6 months of positioning the device. The success rates in the procedure with total occlusion of the aneurysm with a completely open and well-positioned stent with arterial recovery flow corresponded to 91 out of 103 procedures (88.34\%), corresponding to classifications C and D of the OKM. There were 4 subocclusions (3.88\%), and 8 aneurysms did not obtain occlusion (7.76\%), which is 
superior to results found in the first 12 months of a multicenter study ${ }^{17}$ with 113 patients undergoing FRED-STENT intervention demonstrated a high rate of complete aneurysm occlusion in 12 months (73.3\%). In addition to this, the Guimaraens et al. study, in $2020,{ }^{9}$ pointed out the effectiveness of this device in $84.32 \%$ (66\%) of cases, presenting aneurysm occlusion in the $1^{\text {st }}$ year, and $101 / 109(92.7 \%)$ afterwards. Similar results were found in a large multicenter European study, ${ }^{8}$ which indicated $83.9 \%$ efficacy in the $1^{\text {st }}$ year of follow-up. These results confirm that flow deviation is a highly effective technique associated with a remarkably high rate of complete aneurysm occlusion. They also demonstrate that, after the flow deviation, aneurysm occlusion is a relatively slow and progressive process that sometimes takes several months to achieve completion. In our research, following the device selection methodology, the antiplatelet agent and adequate follow-up of patients allowed us to find good results, sometimes better than those in the literature.

Finally, Guimaraens et al., in $2020,{ }^{9}$ pointed out that major complications were observed in 6.5\% of cases: 3 strokes (1 transient ischemic attack, 2 mild strokes), 6 in-stent thrombosis, out of which 3 presented bleeding, but only $1(0.5 \%)$ was clinically relevant. In our study, there were a total of 5 patients (4.85\%) with complications in the intraoperative period. There was poor opening of the stent and dissection of the femoral artery, both with an incidence of $0.97 \%$ of complications. Consequently, there were 2 acute strokes in the postoperative period of up to 7 days, and a carotid-cavernous fistula, being responsible for $1.94 \%$ and $0.97 \%$ of the total complications, respectively. We observed that the complication rate was very close to that observed in the literature, a surgical risk inherent to the highly complex procedure.

\section{Conclusion}

Our study observed that flow redirection is a technique with favorable performance associated with a high rate of complete aneurysm occlusion. Among the options of devices, STENT-FRED presented effectiveness in $88.54 \%$ of the 103 procedures included in this study. In addition, a low rate of serious complications was observed (4.84\%), which indicates this to be an effective option in the treatment of internal carotid aneurysms, reiterating that the aneurysm occlusion is a relatively slow and progressive process that, at times, takes several months to achieve completion. Currently, there is a need for more studies on this type of device, compared with other FR devices. We hope that the present research will help to foster the analysis of this treatment option.

\section{Conflict of Interests}

The authors have no conflict of interests to declare.

Acknowledgment

We acknowledge all participants.

\section{References}

1 Ajiboye N, Chalouhi N, Starke RM, Zanaty M, Bell R. Unruptured cerebral aneurysms: evaluation and management. ScientificWorldJournal 2015;2015:954954. Doi: 10.1155/2015/954954

2 Wang R, Zhang D, Zhao J, Wang S, Zhao Y, Niu H. A comparative study of 43 patients with mirror-like intracranial aneurysms: risk factors, treatment, and prognosis. Neuropsychiatr Dis Treat 2014; 10:2231-2237

3 Griessenauer CJ, Gupta R, Shi S, et al. Collar sign in incompletely occluded aneurysms after Pipeline embolization: evaluation with angiography and optical coherence tomography. AJNR Am J Neuroradiol 2017;38(02):323-326

4 Diaz O, Gist TL, Manjarez G, Orozco F, Almeida R. Treatment of 14 intracranial aneurysms with the FRED system. J Neurointerv Surg 2014;6(08):614-617

5 Möhlenbruch MA, Herweh C, Jestaedt L, et al. The FRED flowdiverter stent for intracranial aneurysms: clinical study to assess safety and efficacy. AJNR Am J Neuroradiol 2015;36(06): 1155-1161

6 Kocer N, Islak C, Kizilkilic O, Kocak B, Saglam M, Tureci E. Flow Redirection Endoluminal Device in treatment of cerebral aneurysms: initial experience with short-term follow-up results. J Neurosurg 2014;120(05):1158-1171

7 Poncyljusz W, Sagan L, Safranow K, Rać M Initial experience with implantation of novel dual layer flow-diverter device FRED. Wideochir Inne Tech Malo Inwazyjne 2013;8(03):258-264

8 Killer-Oberpfalzer M, Kocer N, Griessenauer CJ, et al. European multicenter study for the evaluation of a dual-layer flow-diverting stent for treatment of wide-neck intracranial aneurysms: the European Flow-Redirection Intraluminal Device Study. AJNR Am J Neuroradiol 2018;39(05):841-847

9 Guimaraens L, Vivas E, Saldaña J, et al. Efficacy and safety of the dual-layer flow-diverting stent (FRED) for the treatment of intracranial aneurysms. J Neurointerv Surg 2020;12(05): 521-525

10 Bouthillier A, van Loveren HR, Keller JT. Segments of the internal carotid artery: a new classification. Neurosurgery 1996;38(03): 425-432, discussion 432-433

11 Berg P, Iosif C, Ponsonnard S, Yardin C, Janiga G, Mounayer C. Endothelialization of over- and undersized flow-diverter stents at covered vessel side branches: An in vivo and in silico study. J Biomech 2016;49(01):4-12

12 Mahboobani NR, Chong WH, Lam SSK, Siu JC, Tan CB, Wong YC. Treatment of intracranial aneurysms with flow re-direction endoluminal device-a single centre experience with short-term follow-up results. Neurointervention 2017;12(01):11-19

13 O'kelly CJ, Krings T, Fiorella D, Marotta TR. A novel grading scale for the angiographic assessment of intracranial aneurysms treated using flow diverting stents. Interv Neuroradiol 2010;16 (02):133-137

14 Binh NT, Luu VD, Thong PM, et al. Flow diverter stent for treatment of cerebral aneurysms: A report of 130 patients with 134 aneurysms. Heliyon 2020;6(02):e03356

15 Vlak MHM, Algra A, Brandenburg R, Rinkel GJ. Prevalence of unruptured intracranial aneurysms, with emphasis on sex, age, comorbidity, country, and time period: a systematic review and meta-analysis. Lancet Neurol 2011;10(07):626-636

16 Arena JE, Hawkes MA, Farez MF, et al. Headache and treatment of unruptured intracranial aneurysms. J Stroke Cerebrovasc Dis 2017;26(05):1098-1103

17 Briganti F, Leone G, Marseglia M, et al. Endovascular treatment of cerebral aneurysms using flow-diverter devices: A systematic review. Neuroradiol J 2015;28(04):365-375 